\title{
SAAT: TRANSFORMAÇÃO GENÉTICA MEDIADA POR AGROBACTERIUM APÓS SONICAÇÃO DE EMBRIÕES IMATUROS DE MILHO
}

\author{
MARIA JOSÉ VILAÇA DE VASCONCELOS ${ }^{1}$, MARCELO ANTONIOL FONTES ${ }^{2}$, EDÍLSON \\ PAIVA $^{1}$, CARLOS HENRIQUE SIQUEIRA DE CARVALHO ${ }^{3}$ e SOLANGE MARQUES BARBOSA ${ }^{4}$ \\ ${ }^{1}$ Embrapa Milho e Sorgo, Caixa Postal 151, CEP 35701-970, Sete Lagoas, MG. E-mail: mjose@cnpms.embrapa.br \\ ${ }^{2}$ Bolsista DTI/Pronex \\ ${ }^{3}$ Embrapa Café \\ ${ }^{4}$ Bosista Iniciação científica/Fapemig
}

Revista Brasileira de Milho e Sorgo, v.7, n.2, p. 105-112, 2008

\begin{abstract}
RESUMO - O bombardeamento de partículas e a transformação mediada por Agrobacterium são os dois principais processos para introdução assexuada de genes em milho. Uma nova possibilidade e potencialmente mais eficiente método para transformar plantas via Agrobacterium foi desenvolvido para atingir a célula apropriada do tecido-alvo. Essa nova técnica, chamada transformação mediada por Agrobacterium após sonicação - SAAT, envolve rápidos períodos de ultrassonicação na presença de Agrobacterium. SAAT produz pequenos e uniformes poros ou canais através dos tecidos, permitindo um fácil acesso da Agrobacterium aos tecidos internos das plantas. O objetivo do presente trabalho foi transformar embriões imaturos de linhagens tropicais de milho usando a técnica de SAAT. Embriões imaturos de milho foram cultivados por cinco dias, em meios para indução de calos. Antes do tratamento de SAAT, os embriões foram inoculados com Agrobacterium LBA4404 contendo o plasmídio pCAMBIA C2-208 e submetidos à sonicação por 30 segundos. Foi analisada a expressão transiente em diferentes processos usados para transformação genética, sendo observado que de 37,5 a 87,5\% dos embriões foram positivos para o teste histoquímico da $\beta$ glucuronidase (Gus). Calos resistentes à higromicina, obtidos de meios de cultivo contendo $30 \mathrm{mg} . \mathrm{L}^{-1}$ de higromicina, foram usados para regeneração de plantas em meio basal MS suplementado com 0,5 mg.L-1 IBA (ácido indol butírico) e $1 \mathrm{mg} . \mathrm{L}^{-1}$ BAP (Benzilaminopurina). Foi verificada a expressão de GUS nas folhas das plantas regeneradas e resistentes à higromicina
\end{abstract}

Palavras-chave: Zea mays, transformação genética, embriões imaturos, expressão transiente, ensaios de GUS.

\section{SAAT: SONICATED ASSISTED AGROBACTERIUM-MEDIATED TRANSFORMATION OF TROPICAL MAIZE EMBRYOS}

\begin{abstract}
Particle bombardment and transformation mediated by Agrobacterium are the main processes to introduce gene in maize in an asexual way. Recently, a new and potentially more efficient method for plant transformation via Agrobacterium was
\end{abstract}


developed to reach the proper cells in the target tissue. This technique called Sonicated Assisted Agrobacterium-mediated Transformation (SAAT) involves subjecting the plant tissue to brief periods of ultrasound in the presence of Agrobacterium. SAAT treatment produces small and uniform fissures and channels throughout the tissue, allowing the Agrobacterium easier access to internal plant tissues. The objective of this work was to transform immature embryos of tropical maize inbred lines using the SAAT technique. Immature maize embryos were cultured for five days on callus induction medium. Also, prior to SAAT treatments, embryos were inoculated with Agrobacterium LBA4404 harboring the plasmid pCAMBIA C2-208 and submitted to sonication for 30 seconds. Different transformation parameters were analyzed in transient expression assays and 37.5 to 87.5 percent of embryos showed positive histochemical GUS assay. Resistant calli, obtained from the medium containing $30 \mathrm{mg} . \mathrm{L}^{-1}$ hygromycin were used to regenerate plants in MS basal medium supplemented with $0.5 \mathrm{mg} . \mathrm{L}^{-1}$ IBA (indole butyric acid) and $1 \mathrm{mg} . \mathrm{L}^{-1}$ BAP (Benzylaminopurine). GUS expression was verified in the leaves of plants regenerated and resistant to hygromycin.

Key words: Zea mays, genetic transformation, immature embryos, transient expression, Gus assay.

Existem vários métodos para transformação de plantas, entre eles Agrobacterium (Ishida et al., 1996; Frame et al., 2006), bombardeamento de partículas (Sanford, 1988; Aragão \& Rech, 2001), eletroporação (Fromm et al. 1985, D'Halluin et al., 1992), "silicon carbide fibers" (Kaeppler et al., 1990), transformação mediada por lipossomos (Caboche, 1990), transformação via infiltração a vácuo mediada por Agrobacterium (Bechtold et al., 1993) e transformação via ultra-som Sonication-Assisted Agrobacterium-mediated Transformation - SAAT (Trick \& Finer, 1997; Santarém et al., 1998; Shrestha et al., 2007; Pathak \& Yousif, 2008). O desenvolvimento das técnicas de transformação genética para cereais tem sido relativamente lento, principalmente em conseqüência da sua limitada susceptibilidade à Agrobacterium e baixa capacidade de regeneração de plantas férteis a partir de protoplastos (Rhodes et al., 1988).
A técnica de SAAT (Trick \& Finer, 1997) permite que a Agrobacterium atinja as células mais internas do tecido vegetal, por criar pequenas e uniformes fissuras e canais através dos quais transferem seu DNA para o genoma das plantas. Essa técnica pode ser utilizada em diversos grupos de plantas, como monocotiledôneas, dicotiledôneas e gimnospermas (Trick \& Finer, 1997). Como as monocotiledôneas e certos tecidos de dicotiledôneas não são muito receptivos à transformação mediada por Agrobacterium (Ishida et al., 1996; Danilova, 2007), tanto a bactéria quanto o tecido-alvo a ser transformado podem ser manipulados para que se obtenha um aumento na eficiência de transformação destas plantas. Dentre as técnicas, pode-se citar o uso de compostos fenólicos como acetoseringona, indutor de transferência do TDNA (Stachel et al., 1985), modificações no vetor binário da agrobactéria (Hiei et al., 1994; Ishida et al., 1996), adição de anti-oxidantes no meio de co-cultivo (Perl et al., 1996) e ferimento 
(Horsh et al., 1985; Stachel et al., 1985; Bidney et al., 1992).

Pouco explorado tem sido o uso de sonicação para ferir e modificar o tecido a ser transformado, tanto com DNA isolado (Zhang et al., 1991; Joersbo e Brunstedt, 1992), quanto com Agrobacterium (Trick \& Finer, 1997; 1998).

Neste trabalho, foi avaliado o uso de sonicação, inoculação com Agrobacterium e o efeito do pré-aquecimento do explante-alvo (embriões imaturos) na transformação genética de milho tropical.

Sementes da linhagem de milho L48, com 10 a 15 dias após a fecundação, foram desinfestadas e os embriões, medindo aproximadamente 1,0 a $1,5 \mathrm{~mm}$ de comprimento, foram extraídos e inoculados em meio de cultura contendo os sais básicos de Chu et al. (1975), suplementado com 2,9 g.L $\mathrm{L}^{-1}$ de prolina, $3 \%(\mathrm{p} /$ v) de sacarose, $5 \mathrm{mg} . \mathrm{L}^{-1}$ de tiamina, $2 \mathrm{mg} . \mathrm{L}^{-1} \mathrm{de}$ glicina, $100 \mathrm{mg} . \mathrm{L}^{-1}$ de casaminoácios, $100 \mathrm{mg} . \mathrm{L}^{-1}$ de inositol, $30 \mu \mathrm{M}$ de DICAMBA e $100 \mu \mathrm{M}$ de acetoseringona. Em seguida, foram incubados a $25{ }^{\circ} \mathrm{C}$, por cinco dias, na ausência de luz (Figura 2A). Após esse período, os embriões foram submetidos ao tratamento SAAT com a A. tumefaciens LBA 4404. Foi utilizada a construção C2-208 pCAMBIA contendo região codificante para resistência a higromicina e GUS sob controle do promotor 35S CaMV (Figura 1). As bactérias foram crescidas em meio LB por 16 horas, centrifugadas a $1500 \mathrm{~g}$ por 5 minutos e ressuspensas em meio de cultura contendo os sais básicos de MS (Murashige e Skoog, 1962), suplementado com 3\% (p/v) de sacarose. A suspensão bacteriana foi diluída a $\mathrm{OD}_{600}$, entre $0,5-0,6$, com o mesmo meio líquido. Cinquenta embriões foram transferidos para tubos de microcentrífuga de capacidade de 1,5 mL sendo, em seguida, adicionados 1,0

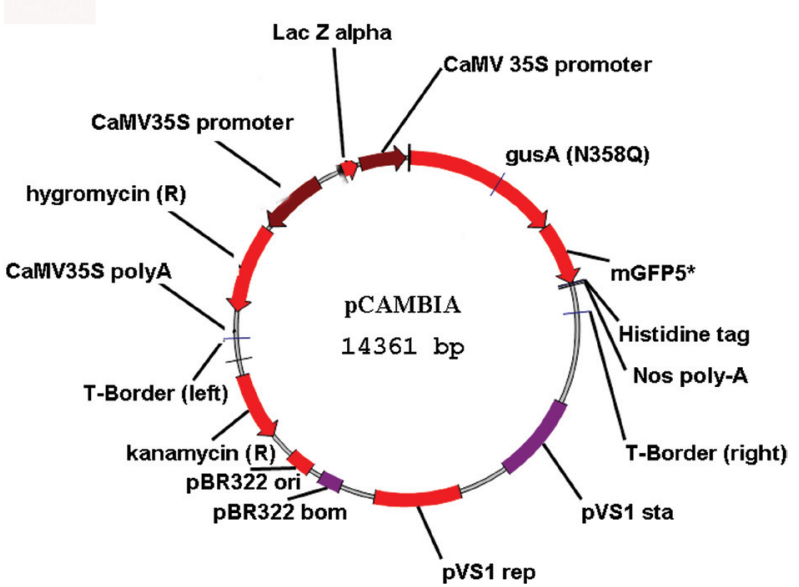

FIGURA 1. Plasmídio pCAMBIA, usado para transformação de milho.

$\mathrm{mL}$ da suspensão bacteriana e submetidos a diferentes tratamentos de ultra-som, conforme Tabela 1.

Após os tratamentos, os embriões foram transferidos para o meio de cultura contendo os sais básicos de Chu et al. (1975), suplementado com $3 \%(\mathrm{p} / \mathrm{v})$ de sacarose, $30 \mu \mathrm{M}$ de Dicamba e $100 \mu \mathrm{M}$ de acetoseringona. Após dois dias, os embriões foram lavados com água destilada autoclavada, secados em papel de filtro estéril e transferidos para meio de Chu et al. (1975), suplementado com 300 mg. $\mathrm{L}^{-1}$ de Timentin. Após dois dias no meio com antibiótico, os embriões foram analisados para a atividade de GUS, de acordo com Jefferson et al.(1987). Após duas semanas, os embriões foram transferidos para o meio de seleção de Chu et al. (1975), suplementado com $10 \mathrm{mg} . \mathrm{L}^{-1}$ de higromicina. Após duas semanas, os calos formados foram transferidos para o meio contendo $20 \mathrm{mg} . \mathrm{L}^{-1}$ de higromicina, permanecendo por mais duas semanas e, em seguida, transferidos para meio contendo $30 \mathrm{mg} . \mathrm{L}^{-1}$ de higromicina.

Os calos embriogênicos formados foram transferidos para meio de regeneração con- 
TABELA 1. Tratamentos utilizados nos experimentos.

\begin{tabular}{|c|c|}
\hline Tratamentos & Descrição do tratamento \\
\hline 01 & Embriões + Agrobacterium + sonicação por 30 segundos \\
\hline 02 & $\begin{array}{l}\text { Embriões + pré-tratamento a } 37{ }^{\circ} \mathrm{C} \text { por } 2,5 \text { minutos + Agrobacterium + sonicação por } 30 \text { segundos + } \\
\text { resfriamento em gelo por um minuto }\end{array}$ \\
\hline 03 & $\begin{array}{l}\text { Embriões + pré-tratamento a } 37^{\circ} \mathrm{C} \text { por cinco minutos + Agrobacterium + sonicação por } 30 \text { segundos } \\
\text { + resfriamento em gelo por um minuto }\end{array}$ \\
\hline 04 & $\begin{array}{l}\text { Embriões + pré-tratamento a } 37{ }^{\circ} \mathrm{C} \text { por dez minutos + Agrobacterium + sonicação por } 30 \text { segundos + } \\
\text { resfriamento em gelo por um minuto }\end{array}$ \\
\hline 05 & Controle (Embriões + Agrobacterium e ausência de Sonicação). \\
\hline
\end{tabular}

tendo os sais básicos de Chu et al. (1975), suplementados com 2\% (p/v) de sacarose, 1,0 mg.L. $\mathrm{L}^{-1}$ de BAP (Benzilaminopurina) e 0,5 mg. $\mathrm{L}^{-1}$ de ácido indol butírico, $300 \mathrm{mg} . \mathrm{L}^{-1}$ de Timentin e $5 \mathrm{mg} . \mathrm{L}^{-1}$ de higromicina, para evitar a formação de regenerantes "escape" (não transformados). As condições de cultivo foram de $25 \pm 2^{\circ} \mathrm{C}$, fotoperíodo de 16 horas e intensidade luminosa em torno de $36 \mu$ moles $\mathrm{m}^{-2} \cdot \mathrm{s}^{-1}$. Com aproximadamente $10 \mathrm{~cm}$ de
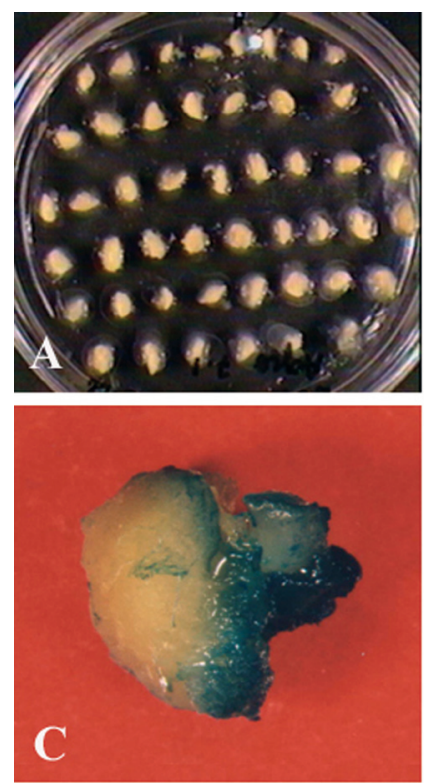

altura, os regenerantes foram individualizados e transferidos para meio de enraizamento contendo os sais básicos de MS na metade da concentração dos sais, suplementado com $1,5 \%(\mathrm{p} / \mathrm{v})$ de sacarose e $1,0 \mathrm{mg} \cdot \mathrm{L}^{-1}$ de ANA (ácido naftaleno acético). Após o processo de enraizamento, as plantas foram retiradas da condição in vitro, as raízes lavadas e plantadas em vasos de plástico contendo a mistura solovermiculita, na proporção 1:1. Em seguida,
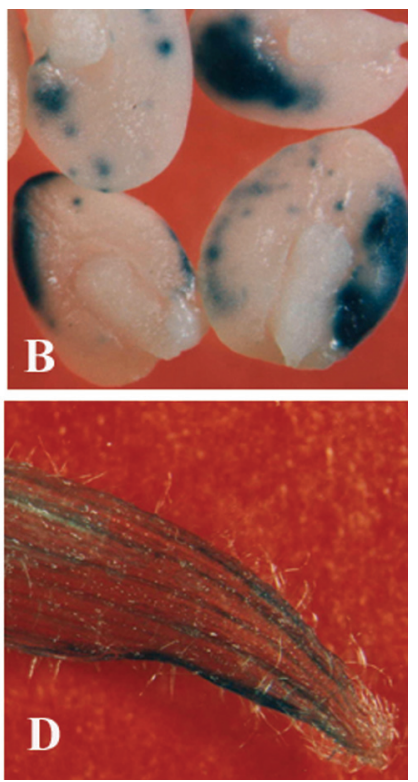

FIGURA 2. Expressão transiente do gene gus em calos de milho. A - Embriões imaturos de milho submetidos à sonicação. B e C - Expressão transiente do gene gus em calos de milho. D Expressão permanente do gene gus em folhas de plantas de milho regeneradas após a transformação genética, pelo método de SAAT. 
foram conduzidas a casa-de-vegetação, para o processo de aclimatação, onde foram irrigadas conforme as necessidades. Após aclimatação das plantas supostamente transformadas (folhas) foram coletadas para os testes histológicos, segundo Jefferson et al.(1987).

As análises dos testes histológicos mostraram que, em todos os embriões, o tratamento com SAAT aumentou o nível para a expressão transiente de GUS, na maioria dos tecidos inoculados com Agrobacterium, e que, na ausência do tratamento com SAAT, a expressão transitória do gene GUS foi muito baixa ou nula, como pode ser observado na Tabela 2. A maioria dos embriões foi positiva para GUS (Figura $2 \mathrm{~B} \mathrm{e} \mathrm{C).} \mathrm{O} \mathrm{melhor} \mathrm{tratamento,}$ segundo dados de expressão transiente, foi o 3 , onde houve um período de pré-aquecimento de cinco minutos antes de ser submetido ao SAAT. Esse aquecimento, provavelmente, tornou a parede e a membrana celular mais permeáveis, favorecendo a transformação. $\mathrm{O}$ tratamento de pré-aquecimento mais drástico, a dez minutos (Tratamento 4) afetou negativamente a eficiência de transformação para expressão transiente quando comparado com os outros tratamentos. Embora resultados de até $87,5 \%$ de expressão transiente tenham sido observados (Tabela 2), não se pode afirmar que houve integração dos genes ao genoma dos embriões. No entanto, as análises histoquímicas confirmaram a expressão do Gus em folhas de milho regeneradas a partir de calos resistentes à higromicina, concluindo que a transferência desses genes para os embriões foi eficiente por esse método. Neste trabalho, não foi possível verificar a penetração das bactérias nas camadas epidérmicas. Dados histológicos obtidos por Trick \& Finer $(1997 ; 1998)$ revelaram alto grau de colonização de bactérias tanto em células epidérmicas quanto em células subepidérmicas, com bactérias chegando a penetrar de 7 a 8 camadas de células.

Após a regeneração (30 dias em casa-devegetação), foram coletadas folhas das plantas para o testes histoquímicos do gene GUS. Foi verificada a expressão do gene gus em folhas de plantas resistentes à higromicina regeneradas a partir de calos supostamente transformados pelo método de SAAT. Como pode ser visto na Figura 2D, as secções de folhas foram completamente coradas de azul. Dados semelhantes foram encontrados por Shrestha et al.(2007), quando fizeram a transformação genética de plantas de Vanda usando método de SAAT.

Como conclusão deste trabalho, pode-se inferir que a técnica de SAAT é uma alternativa para a transformação de plantas, uma vez que os microporos produzidos por ultra-som fazem com que a Agrobacterium atinja, efi-

TABELA 2. Expressão transiente, porcentagem de formação de embriões somáticos e regeneração de plantas de milho (L48) transformados pelo método SAAT

\begin{tabular}{lccc}
\hline Tratamento & X-gluc (\%) & Embriões somáticos (\%) & Regeneração (\%) \\
\hline Trat. 1 C2-208 & 54,5 & 42,5 & 17,6 \\
Trat. 2 C2-208 & 62,5 & 31,0 & 21,4 \\
Trat. 3 C2-208 & 87,5 & 40,0 & 25,0 \\
Trat. 4 C2-208 & 37,5 & 38,5 & 23,5 \\
\hline Controle & 0,0 a 5\% & 75,0 & 38,0 \\
\hline
\end{tabular}


cientemente, os tecidos mais profundos da epiderme, aumentando a freqüência de eventos de transformação. Neste trabalho, os embriões submetidos à sonicação tiveram um aumento na eficiência de transformação mediada por Agrobacterium, sendo que o melhor tratamento foi aquele em que os embriões passaram por um período de pré-aquecimento de cinco minutos antes de serem submetidos ao SAAT.

\section{Agradecimentos}

Ao Dr. R. A Jefferson, que gentilmente doou os plasmídios pCAMBIA à Embrapa Milho e Sorgo. M.A.F. agradece ao Pronex sua bolsa de DTI e SMB agradece à Fapemig a bolsa de iniciação científica.

\section{Literatura Citada}

ARAGÃO, F. J. L.; RECH, E. L. Transgenic common bean (Phaseolus vulgaris L.). In: BAJAS, Y. P. S. (Ed.). Transgenic Crops II. Berlin: Springer Verlag, 2001. p. 269-283. ((Biotechnology in agriculture and forestry, 47).

BECHTOLD, N.; ELLIS, J.; PELLETIER, G. In planta Agrobacterium mediated gene transfer by infiltration of adult Arabidopsis thaliana plants. Comptes rendus de l' Academie des Sciences. Sciences de la vie, Montrouge, v. 316, p. 1194-1199, 1993.

BIDNEY, D.; SCELONGE, C.; MARTICH, J.; BURRUS, M.; SIMS, I.; HUFFMAN, G. Microprojectile bombardment of plant tissues increases transformation frequency by Agrobacterium tumefaciens. Plant Molecular Biology, Dordrecht, v. 18, p. 301-313, 1992.

CABOCHE, M. Liposome-mediated transfer of nuclei acids in plant protoplasts. Physiologia Plantarum, Copenhagen, v. 79, p. 173-176, 1990.

CHU, C. C.; WANG, C. C.; SUN, C. S.; HSÜ, C.; YIN, K. C.; CHU, C. Y.; BI, F. $Y$. Establishment of an efficient medium for anther culture of rice through comparative experiments on the nitrogen sources. Scientia Sinica, Peking, v. 18, p. 659-668, 1975.

DANILOVA, S. A. Technologies for genetic transformation of cereals. Russian Journal of Plant Physiology, New York, v. 54, n. 5, p. 569-581, 2007.

D`HALLUIN, K.; BONNE, E.; BOSSUT, M.; De EUCKELEER, M.; LEEMANS, J. Transgenic maize plants by tissue electroporation. The Plant Cell, Rockville, v. 4, p. 1495-1505, 1992.

FRAME, B. R.; MURRAY, J. M.; FONGER, T. M.; MAIN, M. L.; TAYLOR, K. W.; TORNEY, F. J.; PAZ, M. M.; WANG, K. Improved Agrobacterium-mediated transformation of three maize inbred lines using MS salts. Plant Cell Reports, Berlin, v. 25, p. 1024-1034, 2006.

FROMM, M.; TAYLOR, L. P.; WLBOT, V. Expression of genes transferred into monocot and dico plant cells by electroporation. Proceedings of the National Academy of Sciences of the United States of America, Washington, v. 82, p. 5824-5828, 1985.

HIEI, Y.; OHTA, S.; KOMARI, T.; KUMASHIRO, T. Efficient transformation of rice (Oryza sativa L.) mediated by Agrobacterium and sequence analysis of the 
boundaries of the T-DNA. The Plant Journal, Oxford, v. 6, p. 271-282, 1994.

HORSH, R. B.; FRY, J. E.; HOFFMAN, N. L.; EICHOLTZ, D.; ROGERS, S. G.; FRALEY, R. T. A simple and general method for transferring genes into plants. Science, Washington, v. 227, p. 1229-1231, 1985.

ISHIDA, Y.; SAITO, H.; OHTA, S.; HIEI, Y.; KOMARI, T.; KUMASHIRO, T. High efficiency transformation of maize (Zea mays L.) mediated Agrobacterium tumefaciens. Nature Biotechnology, New York, v. 14, p. 745-750, 1996.

JEFFERSON, R. A.; KAVANAGH, T. A.; BEVAN, M. W. GUS fusions: ß-glucuronidase as a sensitive and versatile gene fusion marker in higher plants. EMBO Journal, Oxford, v. 6, p. 3901-3907, 1987.

JOERSBO, M.; BRUNSTEDT, J. Sonication: a new method for gene transfer to plants. Physiologia Plantarum, Copenhagen, v. 85, p. 230-234, 1992.

KAEPPLER, H. F.; GU, W.; SOMMERS, D. A.; RINES, H. W.; COCKBURN, A. F. Silicon carbide-mediated DNA delivery into plant cells. Plant Cell Reporter, Berlin, v. 9, p. 415-418, 1990.

MURASHIGE, T.; SKOOG, F. A revised medium for rapid growth and bioassays with tobacco tissue cultures. Physiologia Plantarum., Copenhagen v. 15, p. 473-497, 1962.

PATHAK,M. R.; YOUSIF, H. R. An effective method of sonication-assisted Agrobacterium- mediated transformation of chickpeas. Plant Cell, Tissue and Organ Culture, Dordrecht, v. 93, p. 65-71, 2008.

PERL, A.; LOTAN, O.; ABU-ABIED, M.; HOLLAND, D. Establishment of an Agrobacterium-mediated system for grape (Vitis vinifera L.): The role of antioxidants during grape-Agrobacterium interactions. Nature Biotechnology, New York, v. 14, p. 624-628, 1996.

RHODES, C. A.; PIERCE, D. A.; METTLER, I. J.; MASCARENHAS, D.; DETMER, J. J. Genetically transformed maize plants from protoplasts. Science, Washington, v. 240, p. 204-207, 1988.

SANFORD, J. C. The biolistic process. Trends in Biotechnology, Amsterdan, v. 6, p. 299-302, 1988.

SANTARÉM, E. R.; TRICK, H. N.; ESSIG, J. S.; FINER, J. J. Sonication-assited grobacterium-mediated transformation of soybean immature cotyledons: optimization of transient expression. Plant Cell Reports, Berlin, v. 17, p. 752-759, 1998.

SHRESTHA, B. R.; CHIN, D. P.; TOKUHARA, K.; MII, M. Efficient of production of transgenic plantls of Vanda through Sonicated Assisted Agrobacterium-mediated transformation of protocorm-like bodies. Plant Biotechnology, Sheffield, v. 24, p. 429-434, 2007.

STACHEL, S. E.; MESSENS, E.; MONTAGU, M. van; ZAMBRYNSKI, P. Identification of signal molecules produced by wounded plant cells with activate the T-DNA transfer process 
in Agrobacterium tumefaciens. Nature, soybean [Glycine max (L.) Merril] embryogenic London, v. 318, p. 624-629, 1985.

suspension culture tissue. Plant Cell Reports, Berlin, v. 17, p. 482-488, 1998.

TRICK, H. N.; FINER, J. J. SAAT: sonication-assisted Agrobacterium-mediated transformation. Transgenic Research, London, v. 6, p. 329-336, 1997.

ZHANG, L.; CHENG, L.; XU, N.; ZHAO, N.; LI, C.; YUAN, J.; JIA, S. Efficient transformationof tobacco by ultrasonication. Biotechnology, New York, v. 9, p. 996-997, TRICK, H. N.; FINER, J. J. Sonication-assisted 1991.

Agrobacterium-mediated transformation of 